\title{
A Case Study on Boeing's 737 MAX Crisis on Account of Leadership Failure
}

\author{
Subhendu Bhattacharya ${ }^{1 *}$, Y. Nisha ${ }^{2}$ \\ ${ }^{1}$ Assistant Professor, Department of Management, Amity Global Business School, Mumbai, India \\ ${ }^{2}$ Associate Professor, Department of Management, Amity Global Business School, Mumbai, India \\ *Corresponding author: subh.econ@gmail.com
}

\begin{abstract}
American multinational corporation Boeing is one of the reputed organizations in the field of aerospace manufacturing. Since its inception by William Boeing in Seattle, Washington in July 15th, 1916, it has surpassed several milestones and grown from strength to strength. It started its venture in areas such as designing and crafting airplanes, rotorcraft, rockets, satellites and also stepped into production of telecommunications equipment, missiles and made a mark in every field of operation. It has a revered status in Dow Jones Industrial Average and made a glaring presence in the Fortune Global 500 list. But the global recognition got eclipsed after fatal crashes in October 2018 and March 2019. Boeing 737 Max planes remained grounded across the world for more than a year. The culpability was overlooking of safety features, hiding the new anti-stall system from pilots, circumvention of standard certification rigours by Federal Aviation Administration, in the hustle of launching ill-prepared product into the market to beat arch rival Airbus. Product malfunction also hinted at systematic problems that needed to be addressed. The company thereby faced lawsuits and claims for compensation. The investigations by FBI began and the House and Senate panels too joined in the foray. Losses worth billions of dollars had been incurred along with displacement of trust and support of loyal customers, severe decline in share price and market capital and ignominy for being short-sighted and lackadaisical in its approach. The outbreak of global pandemic led to further delay in their recovery as demand for fuel efficient 737 Max plummeted due to fall in oil price and delay or cancellation by airlines in buying Boeing planes without being penalised.
\end{abstract}

Keywords: Boeing company, Delayed recovery, Faulty certification, Loss and defamation, 737 Max Jet, Plane mishap, Quality compromise.

\section{Introduction}

Chicago based Boeing had been a prestigious American multinational for its leading contribution in designing, construction and selling of airplanes, rotorcraft, rockets, satellites, telecommunications equipment, and missiles across the world. It was founded by William Boeing in July 15, 1916 and expanded manifold crossing significant milestones. Boeing maintained its leading market share in North America and Asia Pacific due to heavy investment in research and development. However, the reputation of more than hundred years of this aircraft manufacturing company faced a severe jolt as 346 lives were lost in two fatal crashes of Boeing 737 Max aircrafts in recent past. Lion Air Flight 610 that took off from Jakarta, Indonesia crashed into the Java Sea on October 29th, 2018 killing all 189 passengers and crew. About five months hence, Ethiopian Airlines Flight 302 that took off from Addis Ababa, Ethiopia crashed near the town of Bishoftu ending lives of all 157 people aboard on March 10th, 2019. The two horrific incidents sent a shockwave across the aviation industry worldwide, triggered innumerable investigations and grounded numerous Boeing 737 Max jets globally. Both crashed jets were of fuel-efficient and cost-effective Boeing 737 Max 8 version touted as the bestselling aircraft in the history of Boeing. In spite of two horrific tragedies there was a delayed response from US govt. under President Donald Trump and the Federal Aviation Administration (FAA) refused to act. Investigators suspected technical glitches and latent design flaws in the Boeing 737 Max jet aircrafts. However, Boeing leadership was in denial and shifted the blame onto the pilots. However, the real cause of crisis lied with the unholy culture of the organisation which went onto cover up the fact and compromised ethical standard, integrity and safety and also took value of human lives for granted completely.

\section{Case Presentation}

Since the introduction of 737 class of aircraft in the year 1967, Boeing manufactured and delivered over 10,000 aircrafts to airlines across the world. It turned out to be cash cow of the organisation. The blip in the radar happened when company noticed that rival Airbus launched A320neo jetliner with a claim of being superior fuel efficient short-haul airplane. Senior leaders realized the possible shrink in market share and therefore swung into action. Nine months later, Boeing launched the 737 MAX to take the opponent head-on. Company promoted new jetliner with a hype that new model would be $15 \%$ fuel efficient.

In its rivalry with opponent Airbus to capture the market with fuel efficient short-haul airplane, Boeing overlooked safety standards. Both Boeing and FAA were not meticulous on the integrity and safety context and were in a mad rush to launch the ill-prepared product into the market. Senior leaders were short sighted with its myopic concern of speed and power accompanied with revenue and profit. Boeing had long been 
blighted by culture of concealment, cost cutting and regulatory oversight issues. Production had been halted for beleaguered 737 Max jet in December 2019, market capitalization plummeted by $\$ 55$ billion as stock price plunged by $23 \%$ since the Ethiopian crash in March 2019 which led to Boeing CEO Dennis A. Muilenburg stepping down on charges of gross mismanagement in December 2019. Boeing then suffered from production loss and shrunken market-share due to brand ignominy. The compensation for victims and disgruntled customers ran into millions of dollars and creditors were impatient to collect million-dollar settlement of debt as fear sprouted about collapse of the company. A glimpse of the decadence of the aircraft stalwart Boeing is reflected in the following Exhibit - I.

\section{A. Exhibit I: Boeing Company net profit/loss status}

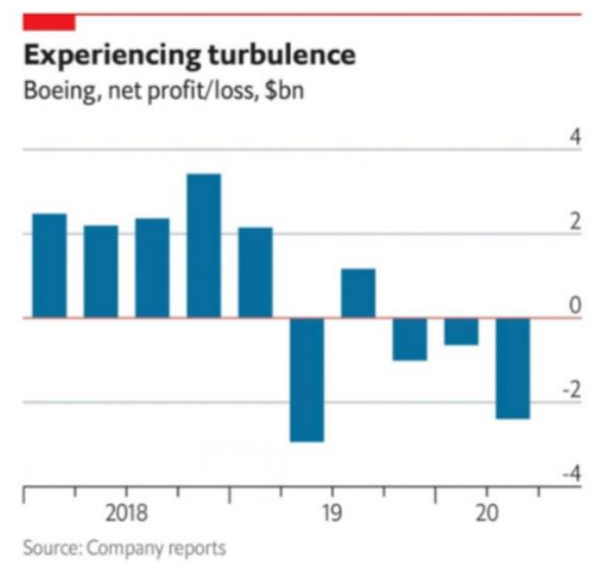

The above exhibit of profit/loss incurred by the Boeing clearly indicates the dwindling status of the American behemoth aerospace manufacturer. Throughout 2018 Boeing registered profit ranging from 2 to more than 3 billion dollars. However, towards the end of 2018 it began its trend of losses which got better in the beginning of 2019 but plunged into losses again after second plane crash in a span of 5 months in March 2019. Investigation, cancellation of order, suspension on delivery, worldwide grounding of Boeing 737 Max jets, litigation expense, hefty compensation to families of crash victims and their families led to the airline incurring significant losses. The situation further aggravated in the wake of the COVID 19 outbreak when the travel ban dimmed the prospect of any quicker recovery in the year 2020. Boeing finally rested on its defence business as revival of Max jet business was delayed.

\section{Management and Outcome}

Boeing which has had a glorious flight since its commencement is facing the worst possible situation post the two horrendous crashes in late 2018 and in the beginning of 2019. Boeing 737 Max jet crash resulted in huge criticism for the company for its reckless and callous corporate culture. The planes were grounded, production got hung up and delivery of Boeing jetliners were deferred. For about 18 months' delivery of 737 Max was stalled which led to net loss of $\$ 2.40$ billion tantamount to $\$ 4.20$ per share. The loss also leads to retrenchment; $10 \%$ jobs were expected to be truncated which would impact 16,000 positions across the company. As per current CEO Dave Calhoun the pandemic wreaked havoc on the company's performance and prospect which led to the announcement of voluntary layoff package for 70,000 employees.

\section{Discussion and Conclusion}

In the history of the corporate world, there are no dearth of cases related to unethical practices, botched-up leadership, compromise on quality, subversion of safety measure and company failure. Boeing's 737 MAX crisis is an addition to this list of debacles. The century old company overlooked its market standing, worldwide reputation and brought unforeseen misfortune with its irreparable indecision. In its urgency to be competitive, comply market demand and outwit opponent, Boeing compelled Federal Aviation Administration for approval of design and issuance of safety certification. There was complete ignorance of problem related to Maneuvering Characteristics Augmentation System anti-stalling system and faulty data feed by Angle of Attack (AOA) sensor. To keep pace with rival Airbus, Boeing didn't care about much-needed pilot training. Boeing even failed to mention about changes in the new model of aircraft in Flight Crew Operations Manual. There was no reference about compulsory flight simulator training. Due to this deliberate suppression of fact, pilot were clueless when the plane behaved erratically midair as bad sensor data remained useless. The inevitable thus happened and the dreadful crashes of Boeing 737 Max aircraft ended the lives of 346 passengers and crew. The condemnable stubborn culture of concealment and denial failed to find the mistake. U.S. Department of Transportation (DOT) unearthed through their investigation the shoddy engineering, undiscerning cost reduction and appeasement of government regulators by the Boeing leadership. The blame was laid to Boeing CEO, Dennis Muilenburg and he was terminated by the board in December 2019. Boeing 737 Max fiasco revealed systemic error of corporate culture, non-compliance of safety and quality measure and overall failure of corporate governance for American aircraft giant. Compensation worth of million dollars, litigation expenses, billions in debt and staggering losses have left unforgettable lessons for the company to learn. Unless the trust of clients, confidence of travellers, and credibility of creditors and respect of investors are restored, Boeing would languish in its indelible blunder in years to come.

\section{References}

[1] Dan Pontefract (2019), 'Boeing's 737 MAX Crisis is a Leadership Issue', Forbes, March 18, 2019. 
[2] Jerry Useem (2019), 'The Long-Forgotten Flight that sent Boeing Off Course', The Atlantic, November 20, 2019.

[3] Dominic Rushe (2020), 'Boeing's 'culture of concealment' led to fatal 737 Max crashes, report finds', The Guardian, March 6, 2020.

[4] Michael Hiltzik (2020), 'Boeing's board shouldn't escape blame in 737 Max scandal', Los Angels Times, January 3, 2020.

[5] Jim Hall and Peter Goelz (2019), 'The Boeing 737 Max Crisis Is a Leadership Failure', New York Times, July 17, 2019.

[6] Emma Newburger, Leslie Josephs (2019), 'What you need to know about Boeing's 737 Max crisis', retrieved from https://www.cnbc.com/2019/05/16/what-you-need-to-know-aboutboeings-737-max-crisis.html, CNBC, May 172019

[7] Chris Isidore (2020), 'The cost of the Boeing 737 Max crisis: $\$ 18.7$ billion and counting', retrieved from https://edition.cnn.com/2020/03/10/business/boeing-737-maxcost/index.html, CNN Business, March 10, 2020.

[8] Al Root (2020), 'Boeing Has More 787 Problems. Here's What That Means for the Stock', retrieved from https://www.barrons.com/articles/boeing-has-more-787-problems-whatthat-means-for-the-stock-51599573414, Barrons.com, September 8, 2020

[9] Dick Nolan (2009), 'Is Boeing's 787 Dreamliner a Triumph or a Folly?', Harvard Business Review, December 23, 2009.

[10] Sandra J. Sucher (2019), 'How Boeing Should Have Responded to the 737 Max Safety Crisis', Harvard Business Review, March 14, 2019.

[11] Chris Isidore (2020), 'Boeing discloses new flaw with 787 jet as problems mount', CNN Business, September 8, 2020. 